\title{
Comparison of Two Segment Combined Instrumentation and Fusion versus Three Segment Posterior Instrumentation in Thoracolumbar Burst Fractures: A Randomized Clinical Trial with 10 Years of Follow Up
}

\author{
Gurkan GUMUSSUYU ${ }^{1}$, Nazir Cihangir ISLAM², Ozkan KOSE³ ${ }^{3}$ Mutlu GUNGOR ${ }^{4}$, Hakan OZCAN ${ }^{5}$ \\ ${ }^{1}$ Istinye University, School of Medicine, Department of Orthopaedics and Traumatology, Bahcelievler Medicalpark Hospital, Istanbul,Turkey \\ ${ }^{2}$ Kafkas University, School of Medicine, Department of Orthopaedics and Traumatology, Kars, Turkey \\ ${ }^{3}$ Antalya Training and Research Hospital, Department of Orthopaedics and Traumatology, Antalya, Turkey \\ ${ }^{4}$ Esnaf Hospital, Orthopaedics and Traumatology Clinic, Mugla, Turkey \\ ${ }^{5}$ Ordu University, School of Medicine, Department of Orthopaedics and Traumatology, Ordu, Turkey
}

This study has been presented at the $11^{\text {th }}$ International Turkish Spine Congress between 29 April and 3 May 2015 at Izmir, Turkey.

Corresponding author: Gurkan GUMUSSUYU gurkangum@yahoo.com

\section{ABSTRACT}

AIM: To compare the clinical and functional outcomes between combined anterior and posterior 2-segment spinal fusion and posterior 3-segment spinal fusion in patients with thoracolumbar (TL) burst fractures at risk for posttraumatic kyphosis without neurological deficit.

MATERIAL and METHODS: Twenty-seven patients with TL burst fracture, $>20^{\circ}$ kyphosis and/or $50 \%$ collapse, and posterior ligament injury, but without neurological deficit, were randomly assigned into posterior and combined groups. Posterior treatment was 3-segment (1 level below, fractured level and 2 levels above) posterior spinal fusion. Combined treatment was including $1 \mathrm{cranial}$ and 1 caudal levels posterior spinal fusion, followed by anterior corpectomy, cage, and bone grafting. Patients were followed-up for a mean duration of $117.7 \pm 8.7$ months (range, 98-132 months). At the final follow-up, the clinical and functional means of the groups were compared using degree of kyphosis, visual analogue scale (VAS), and Roland-Morris and Oswestry scores.

RESULTS: Mean patient age was $38.5 \pm 2.4$ years (range: 18-68 years). Fourteen and 13 patients were treated with the combined and posterior approach, respectively. Age (40.0 \pm 10.3 and $37.0 \pm 14.2$ years; $p=0.519)$, sex (female/male, $3: 10$ and 5:9; $p=0.385)$, mechanism of injury ( $p=0.513)$, fractured levels $(p=0.185)$, type of fracture $(p=0.293)$, degree of kyphosis at initial admission $(p=0.616)$, collapse $(p=0.155)$, canal narrowing $(p=0.280)$, follow-up $(p=0.076)$ and accompanied limb fracture $(p=0.374)$ were similar between groups. Duration of hospital stay was similar between two groups $(p=0.102)$. However, blood loss was higher in combined group (195 ml versus $358 \mathrm{ml}, p=0.003$ ). A $14.2^{\circ}$ correction was achieved in the posterior group and $16.9^{\circ}$ in the combined group $(p=0.61)$. Loss of correction at the last follow-up visit was $2.1^{\circ}$ with a final kyphosis of $7.2^{\circ}$ in the posterior group, and $1.2^{\circ}$ with a final kyphosis of $5.5^{\circ}$ in the combined group. The differences in the correction of kyphosis $(p=0.616)$, postop kyphosis $(p=0.756)$, loss of correction $(p=0.141)$ and final kyphosis $(p=0.085)$ between the treatment groups were not significant. At the last follow-up visit of the posterior and combined groups, the VAS ( $16.4 \pm 14.8$ vs. $17.6 \pm 16.6$; $p=0.685)$, Roland-Morris $(27.2 \pm 27.3$ vs. $29.6 \pm 20.5$; $p=0.519)$, and Oswestry scores $(15.0 \pm 13.1$ vs. $17.7 \pm 11.5 ; p=0.302)$ were similar.

CONCLUSION: Both treatment methods are similar in terms of clinical and functional outcomes.

KEYWORDS: Thoracolumbar burst fracture, Anterior, Posterior, Fusion, Randomized clinical trial

Gurkan GUMUSSUYU (D): 0000-0001-8408-9521 Nazir Cihangir ISLAM D : 0000-0002-6718-1681
Ozkan KOSE (D) : 0000-0002-7679-9635 Mutlu GUNGOR (1) : 0000-0002-7512-0248
Hakan OZCAN (1) : 0000-0002-0775-5575 


\section{- INTRODUCTION}

$\mathrm{M}$ ost spinal fractures occur in the thoracolumbar (TL) junction, where a relatively rigid and kyphotic thoracic spine continues with a mobile and lordotic lumbar spine. Around 10\%-20\% of these fractures are bursttype fractures and involves at least 2 of 3 segments of the vertebral column, as described by Denis et al. $(6,7)$. Although these fractures are relatively frequent injuries of the spine, they pose a challenge to the treating physician owing to the controversy remaining over the indications and therapeutic options, particularly in patients without neurological deficit $(24,32)$.

Currently, there are 2 main controversies about the management of TL burst fractures. The first is the indication for surgical treatment vs. conservative treatment. In other words, we need to answer this question first: "Which patients are candidates for surgery, and which patients should be treated nonoperatively?". Earlier definitions and classifications of vertebral fractures focused on the morphology of the fracture but could not guide the treatment $(7,13,15-17)$. Several previous studies have shown that both conservative and surgical treatments of TL burst fractures without neurological deficit were equally effective. Thus, conservative treatment is usually advocated to patients with stable TL burst fractures without neurological deficit $(1,9)$.

However, with greater understanding of the biomechanics of the spine in the last 2 decades, the concept of stability has changed. Recently, the Spine Trauma Group developed a new scoring system that provided objective criteria to guide the treatment. According to this new scoring system, called the Thoracolumbar Injury Classification and Severity Score (TLICS), patients were evaluated by 3 major parameters, namely morphology of the fracture, integrity of posterior ligamentous complex (PLC), and neurological status. Points are assigned for each category, and the final total points suggest a possible treatment option. Patients who are scored 3 points or lower are considered as nonoperative candidates, whereas patients with 5 points or more are operative candidates. Patients with a total score of 4 fall into an indistinct category, where either nonoperative or operative treatment may be considered based on other clinical parameters such as accompanying comorbidities (Table I) $(27,28)$. Currently, TLICS is widely accepted and is beginning to be used clinically, and it appears to be helping surgeons answer the first question.

The second controversial issue is choosing the optimal technique when surgical treatment is chosen. The second question is: "Which surgical technique is best for my patient?". Burst fractures with PLC injury are unstable fractures and carry the risk of progression of neurological deficit and kyphotic deformity; thus, surgical stabilization should be chosen in these patients (28). An ideal surgical treatment should effectively correct the deformity, provide initial stability, induce neurological recovery, decrease requirements of external immobilization, allow return to work, and be associated with minimal risk of complication. Posterior, anterior, or combined surgeries are the different treatment options for segmental fusion, and all carry different benefits and risks in the achievement of the above-mentioned goals. However, fusion restricts spinal movements and has negative impact on the neighboring mobile segments in the long term, such as adjacent-level disc degeneration (30). Therefore, performing less spinal segmental fusion is advantageous. However, optimal treatment should also remain stable until fusion takes place and prevent kyphotic deformity.

According to a study, short-segment posterior instrumentation and fusion ( 1 level above and 1 level below) for TL burst fractures has a high rate of failure even with transpedicular intracorporal grafting (2). More segments are needed for the fusion site to prevent kyphotic deformity when posterior-only instrumentation and fusion is the treatment chosen. In general, posterior instrumentation with 1 lower level and 2 upper levels or 2 lower and 2 upper levels is advocated (26). However, several authors proposed combined short instrumentation and fusion as the most stable treatment method if short-segment fusion is desired $(10,18,21)$. Unfortunately, the choice of operative technique remains controversial, and there are very few studies that provide strong evidence to clarify this subject in the current literature.

Table I: Thoracolumbar Injury Classification and Severity Score and Treatment Recommendations $(27,28)$

\begin{tabular}{|c|c|}
\hline Parameter & Points \\
\hline \multicolumn{2}{|l|}{ Morphology } \\
\hline Compression & 1 \\
\hline Burst & 2 \\
\hline Translation/rotation & 3 \\
\hline Distraction & 4 \\
\hline \multicolumn{2}{|l|}{ Integrity of the PLC } \\
\hline Intact & 0 \\
\hline Suspected & 2 \\
\hline Injured & 3 \\
\hline \multicolumn{2}{|l|}{ Neurological status } \\
\hline Intact & 0 \\
\hline Nerve root & 2 \\
\hline Complete cord or conus medullaris & 2 \\
\hline Incomplete cord or conus medullaris & 3 \\
\hline Cauda equina & 3 \\
\hline \multicolumn{2}{|l|}{ Recommendations } \\
\hline Total Score & Treatment \\
\hline$\leq 3$ & Conservative \\
\hline 4 & Decision \\
\hline $4<$ & Surgery \\
\hline
\end{tabular}


The purpose of this randomized clinical trial is comparing the clinical and the functional outcomes between combined anterior and posterior 2-segment instrumentation with fusion and posterior 3-segment instrumentation with fusion in $\mathrm{TL}$ burst fractures carrying the risk of posttraumatic kyphosis without any neurological deficit. Our hypothesis was that the shortest and circumferential fusion would provide the best clinical and radiological outcomes in long-term follow-up.

\section{MATERIAL and METHODS}

From September 2003 to July 2006, 27 patients aged between 18 and 70 years with TL (T12-L2) burst fracture, $20^{\circ}$ local kyphosis angle and/or $50 \%$ collapse, and posterior ligament injury, without any neurological deficit, were included to the study regardless of the degree of canal narrowing. Patients who had open spine fracture, neurological deficit, bowel/ bladder dysfunction, head trauma, additional spine fracture, previous back injury or disability, osteoporotic or pathologic fractures, or illness that prevents surgical treatment were excluded. This study was carried out in accordance with the ethical standards of the 1964 Declaration of Helsinki and its later amendments. Our institutional review board approved the study protocol (no: 145.0620), and all patients gave informed consent before their inclusion in the study. After we obtained informed consent from the patients, they were assigned into posterior and combined groups by flipping a coin (Figure 1).

\section{Surgical Technique and Follow-up}

The posterior treatment protocol was 3-segment posterior instrumentation and fusion by transpedicular screws. In this group, fractured vertebra, 1 lower, and 2 upper levels were instrumented and fused using transpedicular screws. No distraction forces were applied during instrumentation. Sagittal alignment was achieved by hyperextending the patient on the operation table during surgery. The combined treatment group was instrumented and fused posteriorly using transpedicular screws from 1 level above to 1 level below the fracture site. Anterior corpus screws to the upper and lower adjacent levels with an anterior rod and anterior corpectomy cages with bone graft to the corpectomy site were added, with application of distraction to reduce kyphotic deformity (Figure 2). Blood loss was estimated by evaluating the amount of blood in the suction canister and that in the soaked lap pads. Surgeries were applied by the same surgeon with the assistance of the same surgical and anesthesiology team in the same hospital. All patients wore thoracolumbosacral orthosis for two months.

\section{Radiological Evaluation}

Radiological measurements and assessments were performed on lateral plain radiographs, computed tomography (CT) and magnetic resonance imaging (MRI) (when available). Collapse rate was measured on plain radiographs. The length of the anterior wall of the fractured vertebra was divided by the mean length of the anterior wall of the vertebrae 1 level above and 1 level below the treated vertebra. Cobb's technique was used to calculate the segmental kyphotic angle across the fractured level, and the measurement was taken from the superior end plate of the vertebrae above and the inferior endplate of the vertebrae below the treated vertebra (Figure 3). Spinal canal compromise was measured at the widest area on coronal

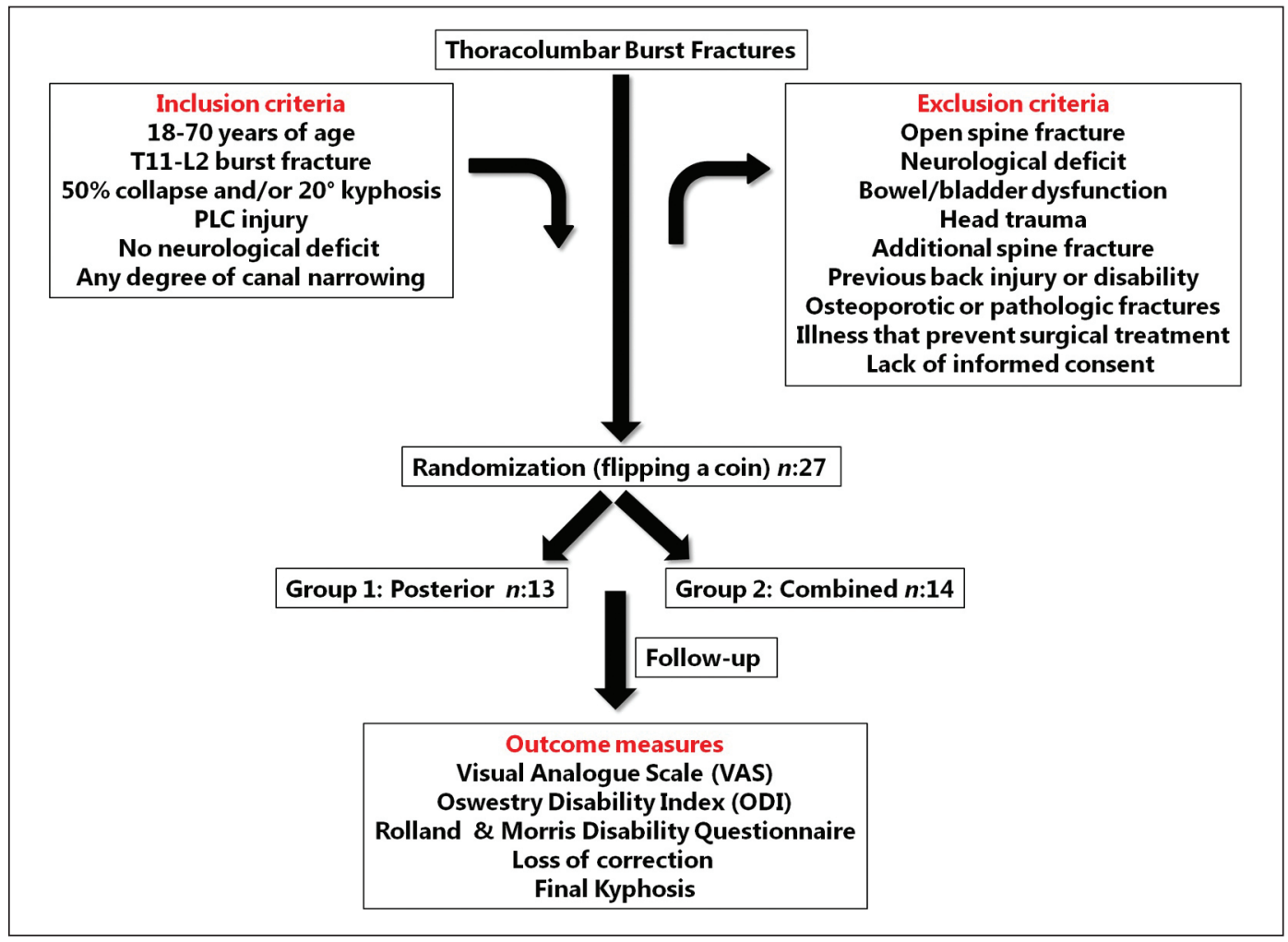

Figure 1: Randomization schema that shows the flow of patients. 


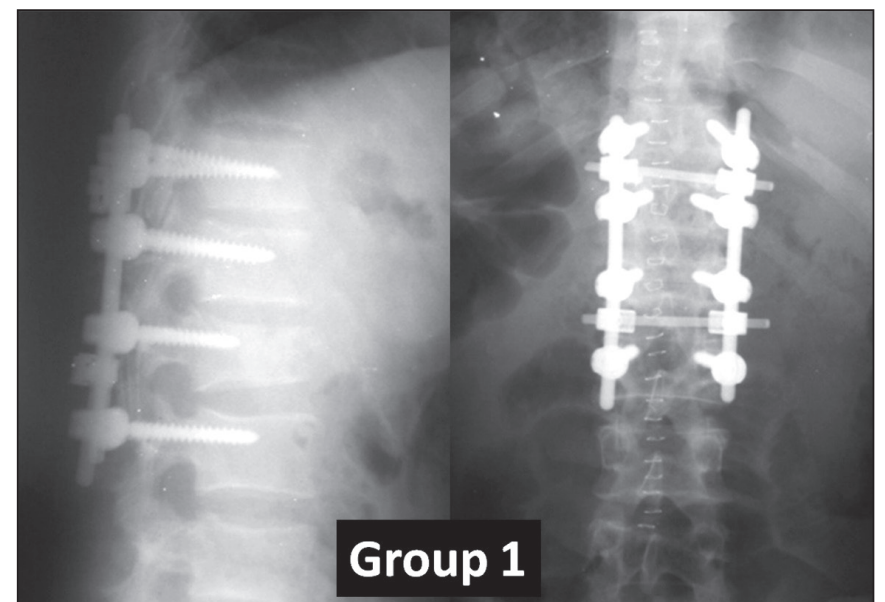

Group 2

Figure 2: Lateral (left) and anteroposterior (right) X-rays of the treated patients in Group 1 (above) and Group 2 (below). computed tomographic (CT) images, and the canal diameter at the level of injury was divided by the average diameter of the anteroposterior canal of the 2 adjacent vertebrae (Figure 4). The measurements were carried out by the orthopedic surgeon (GG) who was familiar with the techniques. PLC injury was evaluated through MRI of PLC components disrupted by posterior edema, comparison of the interspinous space 1 level above and 1 level below on anteroposterior plain radiograph, and CT of the diastasis of the facet joints. Furthermore, PLC injury was confirmed during surgery in all patients.

\section{Outcome Measures}

All patients were followed up with a mean duration of $117.7 \pm$ 8.7 months (range, 98-132 months). At the final follow-up, the clinical and functional means of the groups were compared using degree of kyphosis, visual analogue scale (VAS), Roland and Morris disability questionnaire, and Oswestry Disability Index (ODI).

\section{Statistical Analysis}

Two sample t-test, paired t-test, chi-square, and Mann Whitney $U$ test were used for the statistical analysis $(a=0.05)$.

\section{RESULTS}

A total of 27 patients ( 8 women and 19 men; mean age: 38.5 \pm 12.4 years; range: $18-68$ years) participated in this study. Fourteen patients were treated with the combined approach, and the remaining 13 were treated with the posterior approach. Age $(40.0 \pm 10.3$ and $37.0 \pm 14.2$ years; $p=0.519)$, sex (female/ male, $3: 10$ and $5: 9 ; p=0.385)$, mechanism of injury $(p=0.513)$, fractured levels $(p=0.185)$, type of fracture $(p=0.293)$, degree of kyphosis at initial admission $(p=0.616)$, collapse $(p=0.155)$, canal narrowing $(p=0.280)$, follow-up $(p=0.076)$ and accompanied limb fracture $(p=0.374)$ were similar between

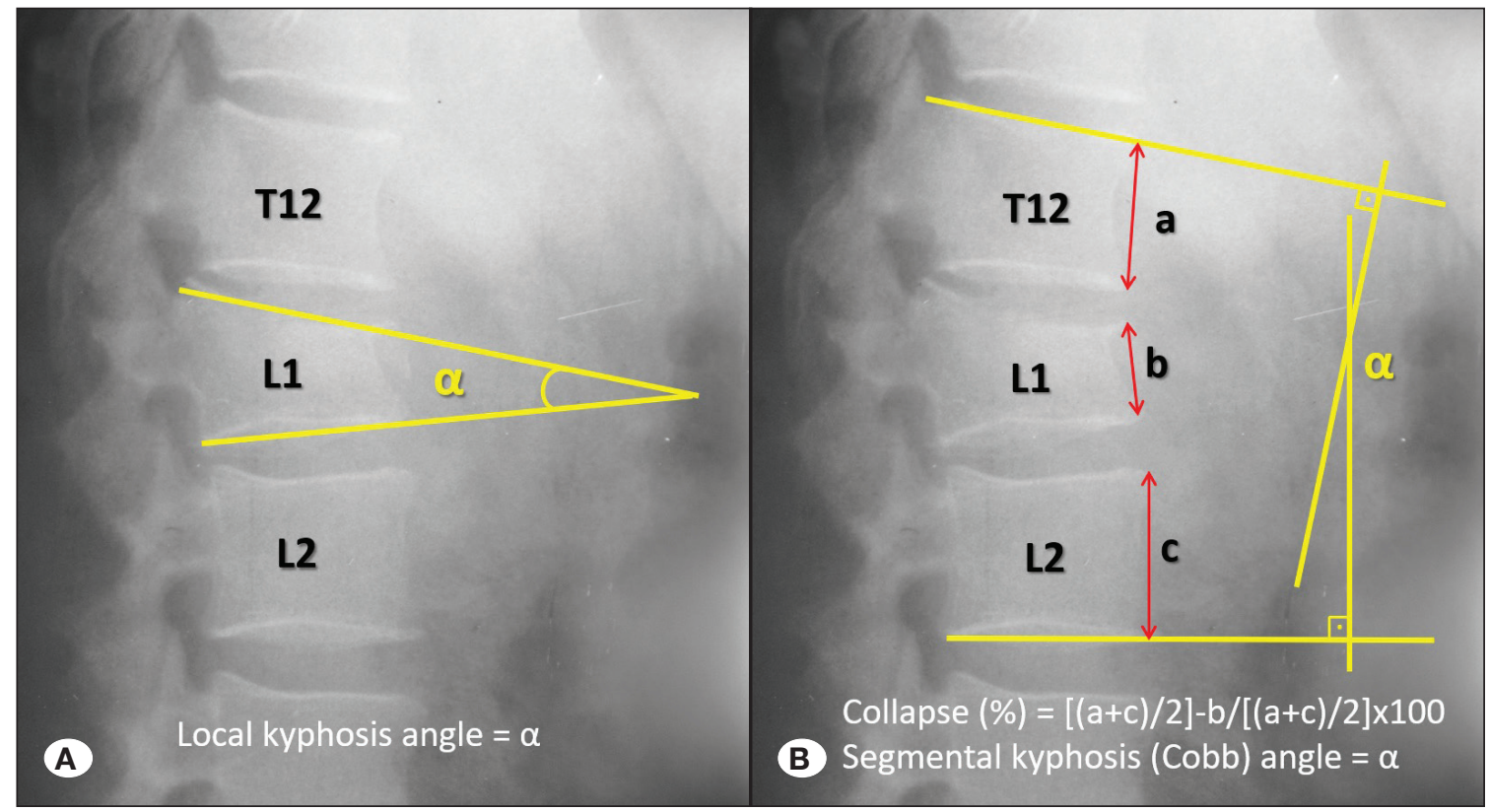

Figure 3: A)

Measurement of local kyphosis angle,

B) measurement of segmental kyphosis angle (Cobb angle) and percentage of collapse. 
groups. Duration of hospital stay was similar between groups $(p=0.102)$. However, blood loss was higher in combined group (195 $\mathrm{ml}$ versus $358 \mathrm{ml}, \mathrm{p}=0.003$ ) (Table II).

Preoperative local kyphosis for the posterior and combined treatment groups was $19.3^{\circ} \pm 6.2^{\circ}$ and $20.3^{\circ} \pm 5.9^{\circ}$, respectively $(p=0.616)$. A $14.2^{\circ}$ correction was achieved in the posterior group and $16.0^{\circ}$ in the combined group postoperatively. Loss of correction at the last follow-up visit was $2.1^{\circ}$, with a final kyphosis of $7.2^{\circ}$, in the posterior group and $1.2^{\circ}$, with a final kyphosis of $5.5^{\circ}$, in the combined group. The differences in the correction of kyphosis $(p=0.616)$, postop kyphosis $(p=0.756)$, loss of correction $(p=0.141)$ and final kyphosis $(p=0.085)$ between the treatment groups were not significant (Table III).

At the last follow-up visit of the posterior and combined groups, the VAS (16.4 \pm 14.8 vs. $17.6 \pm 16.6 ; p=0.685)$, Roland-Morris (27. \pm 27.3 vs. $29.6 \pm 20.5 ; p=0.519)$, and Oswestry scores $(15.0 \pm 13.1$ vs. $17.7 \pm 11.5 ; p=0.302)$ were similar (Table IV).

One temporary nerve root irritation and one ileus occurred during early postoperative period in posterior and combined groups, respectively. One deep infection occurred in combined group. In the deep infection case, the posterior instruments were removed at the fourteenth month postoperatively with a solid posterior fusion. No additional intervention was performed thereafter. Number of complications was not different between treatment groups $(p=0.698)$.

\section{- DISCUSSION}

TL burst fractures in patients without neurological deficit but who carries the risk of posttraumatic kyphosis is a dilemma for the surgeon in terms of surgical management. If surgical treatment is chosen, the question of which surgical technique (posterior, anterior, or combined) to use arises. Short combined instrumentation and fusion (circumferential stabilization and fusion) is advocated by some surgeons as the most stable and shortest construct for TL burst fractures $(10,18,21)$. The goal of this study was to answer whether sacrificing 1 more segment with posterior-only surgery can give better clinical/functional outcome than that of short combined instrumentation and fusion (strongest available option) for TL burst fractures without neurological impairment.

The results of this study revealed that 3-segment posterior instrumentation and fusion, and short combined instrumentation and fusion are similar in terms of clinical and functional outcomes. However, some technical points should be underlined. Sagittal realignment is the main goal in the treatment of TL burst fractures. Anterior support is necessary for the preservation of alignment gained during surgery. However, in posterior-only surgery, distraction further weakens the anterior support. Therefore, technically, no distraction forces were applied during posterior-only surgery. The collapsed vertebral body was used as the anterior support of the posterior construct. Reyes-Sanchez et al. performed vertebral shortening by a posterior approach and transpedicular fixation with plates. They reported less than $1^{\circ}$ of residual kyphosis after the 2-year follow up (19). Second technical point is the use of fracture level screw combination that reinforced the construct. Guven et al. compared posterior instrumentation and fusion with or without fracture level screw combination. They reported better intraoperative correction and maintenance in the treatment of unstable TL burst fractures (11). Thus, maintenance of anterior support together with instrumentation of fractured vertebra in posterior group may explain why both groups resulted with similar results regarding final kyphosis in our study.

In current literature, few studies compared posterior and combined surgeries for the treatment of TL burst fractures (Table V) $(3-5,21,23,29)$. Most of these studies were retrospective and the several preoperative characteristics of included patients were different between each other regarding neurological status and fracture type. There was a tendency towards anterior and combined surgeries when the fracture is unstable accompanied with neurologic deficit. Thus, these studies have serious bias in patient selection. There is only one RCT conducted by Wang and Liu in 2015 (29). They reported similar radiological (kyphosis) and functional results (VAS) in combined and anterior treatment groups which was statistically better than posterior group. However, blood loss,

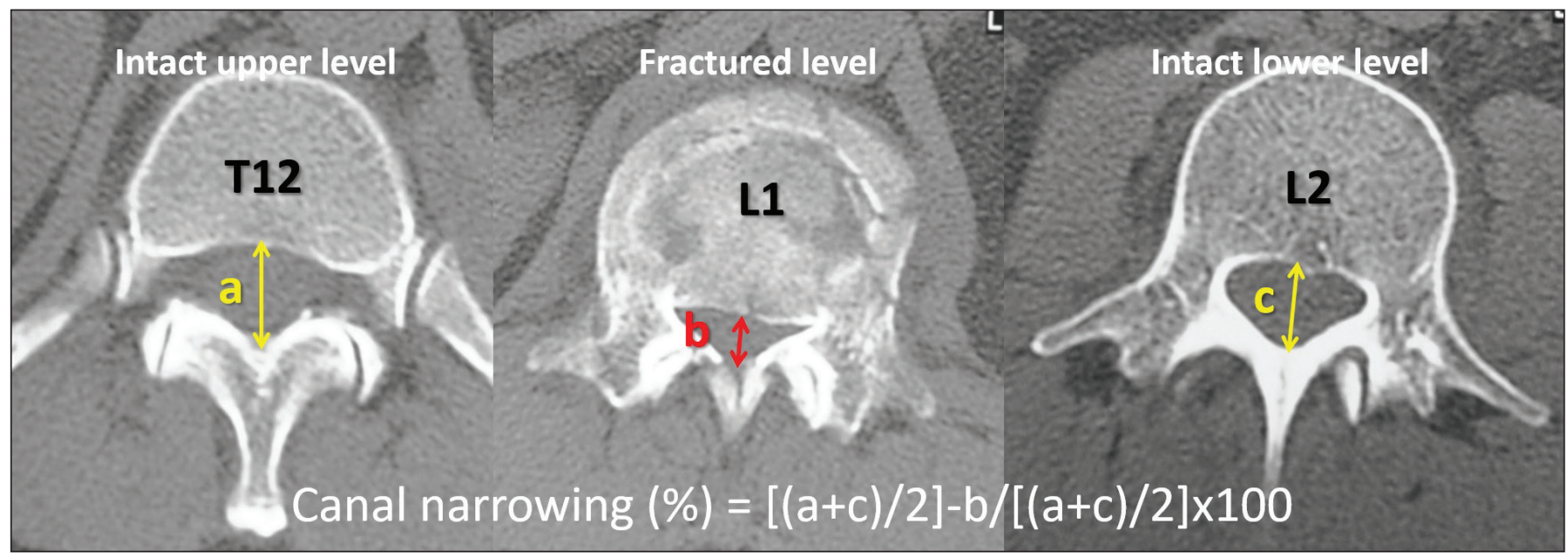

Figure 4: Measurement of percentage of canal narrowing. 
Gumussuyu G. et al: Thoracolumbar Burst Fractures

Table II: Comparison of Demographic and Clinical Characteristics of Patients in Treatment Groups

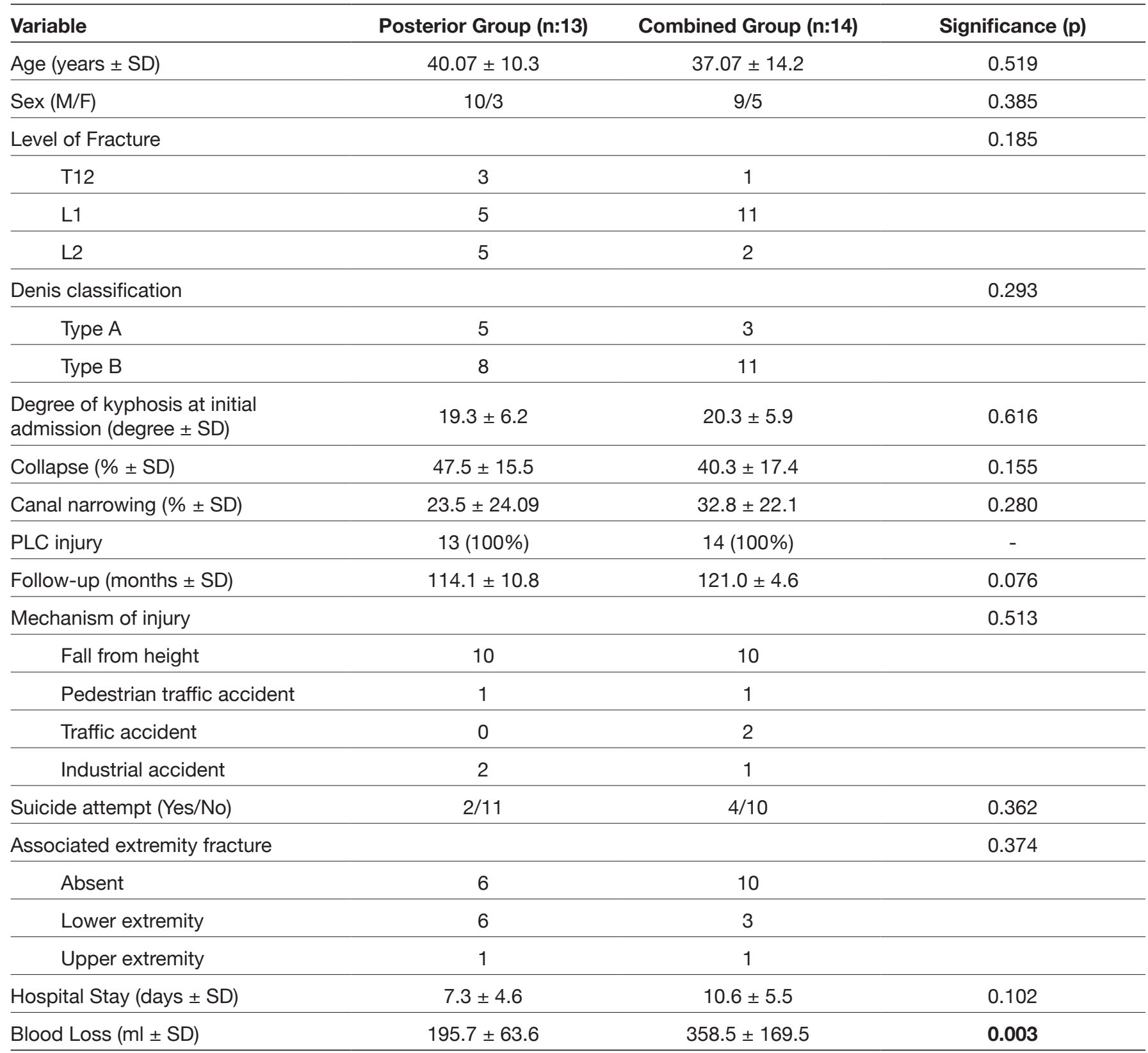

PLC: Posterior ligamentous complex.

Table III: Assessment of Kyphosis During the Study Period

\begin{tabular}{lccccc}
\hline Degree \pm SD & Preop kyphosis & Correction & Postop kyphosis & Loss of correction & Final kyphosis \\
\hline Posterior & $19.3 \pm 6.2$ & $14.2 \pm 5.3$ & $5.0 \pm 4.3$ & $2.1 \pm 1.9$ & $7.2 \pm 3.3$ \\
\hline Combined & $20.3 \pm 5.9$ & $16.0 \pm 5.7$ & $4.2 \pm 3.5$ & $1.2 \pm 2.3$ & $5.5 \pm 4.9$ \\
\hline$p$ & 0.616 & 0.616 & 0.756 & 0.141 & 0.085 \\
\hline
\end{tabular}


Table IV: Comparison of Functional Outcome Variables at Final Follow-up

\begin{tabular}{lccc}
\hline Variable & Posterior Group & Combined Group & p \\
\hline VAS $(\mathrm{mm} \pm \mathrm{SD})$ & $16.4 \pm 14.8$ & $17.6 \pm 16.6$ & 0.685 \\
\hline ODI (value \pm SD) & $15.0 \pm 13.1$ & $17.7 \pm 11.5$ & 0.302 \\
\hline RM (value \pm SD) & $27.2 \pm 27.3$ & $29.6 \pm 20.5$ & 0.519 \\
\hline
\end{tabular}

VAS: Visual Analogue Scale, ODI: Oswestry Disability Index, RM: Roland and Morris disability questionnaire.

Table V: Previously Reported Studies That Compared Combined, Anterior and Posterior Fusion for Unstable TL Fractures in Current English Literature

\begin{tabular}{|c|c|c|c|c|c|c|}
\hline Author & Design & $\begin{array}{l}\text { Treatment } \\
\text { Groups }\end{array}$ & $\begin{array}{l}\text { Number of } \\
\text { patients }\end{array}$ & $\begin{array}{l}\text { Outcome } \\
\text { measures }\end{array}$ & Follow-up & Results \\
\hline $\begin{array}{l}\text { Danisa } \\
\text { et al. (5) }\end{array}$ & $\mathrm{R}$ & $\begin{array}{l}\text { Combined vs } \\
\text { Posterior vs } \\
\text { Anterior }\end{array}$ & 6 vs 27 vs 16 & $\begin{array}{l}\text { Kyphosis, } \\
\text { Duration of } \\
\text { operation, } \\
\text { Hospital stay, } \\
\text { Blood loss, Denis } \\
\text { pain and work } \\
\text { scale }\end{array}$ & 27 months & $\begin{array}{l}\text { No significant intergroup differences } \\
\text { in postoperative kyphotic correction, } \\
\text { neurological function, pain assessment, } \\
\text { or the ability to return to work. Posterior } \\
\text { surgery, however, takes the least time, } \\
\text { causes the least blood loss, and is the least } \\
\text { expensive of the three procedures }\end{array}$ \\
\hline $\begin{array}{l}\text { Schnee } \\
\text { and Ansel } \\
\text { (22) }\end{array}$ & $\mathrm{R}$ & $\begin{array}{l}\text { Combined vs } \\
\text { Posterior vs } \\
\text { Anterior }\end{array}$ & 9 vs 2 vs 14 & $\begin{array}{l}\text { Kyphosis, The } \\
\text { Prolo outcome } \\
\text { scale }\end{array}$ & 16 months & No statistical analysis were performed \\
\hline $\begin{array}{l}\text { Been and } \\
\text { Bauma (3) }\end{array}$ & $\mathrm{R}$ & $\begin{array}{l}\text { Combined vs } \\
\text { Posterior }\end{array}$ & 27 vs 19 & $\begin{array}{c}\text { Union, Kyphotic } \\
\text { deformity, Pain } \\
\text { and complication } \\
\text { rate }\end{array}$ & 72 months & $\begin{array}{c}\text { Clinical results were similar but loss of } \\
\text { reduction }>5^{\circ} \text { was more prevalent in } \\
\text { posterior group }\end{array}$ \\
\hline $\begin{array}{l}\text { Briem } \\
\text { et al. (4) }\end{array}$ & $\mathrm{R}$ & $\begin{array}{l}\text { Combined vs } \\
\text { Posterior }\end{array}$ & 10 vs 10 & $\begin{array}{l}\text { Kyphosis, Sagittal } \\
\text { Index, SF-36 }\end{array}$ & 39 months & $\begin{array}{l}\text { Clinical results were similar but significant } \\
\text { loss of correction in posterior group }\end{array}$ \\
\hline $\begin{array}{l}\text { Wang and } \\
\text { Liu (29) }\end{array}$ & $\mathrm{RCT}$ & $\begin{array}{l}\text { Combined vs } \\
\text { Posterior vs } \\
\text { Anterior }\end{array}$ & 21 vs 23 vs 22 & $\begin{array}{l}\text { Kyphosis, VAS, } \\
\text { operation time, } \\
\text { blood loss }\end{array}$ & 60 months & $\begin{array}{c}\text { Kyphosis and VAS was higher in posterior } \\
\text { group, but blood loss was lower and } \\
\text { operation time was shorter }\end{array}$ \\
\hline $\begin{array}{l}\text { Shin et al. } \\
(23)\end{array}$ & $\mathrm{R}$ & $\begin{array}{l}\text { Combined vs } \\
\text { Posterior }\end{array}$ & 11 vs 35 & $\begin{array}{l}\text { Kyphosis, blood } \\
\text { loss, operation } \\
\text { time, neurological } \\
\text { recovery }\end{array}$ & 15 months & $\begin{array}{l}\text { No significant difference was seen } \\
\text { regarding kyphosis and neurological } \\
\text { recovery but blood loss and operation time } \\
\text { was higher in combined group }\end{array}$ \\
\hline $\begin{array}{l}\text { Current } \\
\text { study }\end{array}$ & $\mathrm{RCT}$ & $\begin{array}{l}\text { Combined vs } \\
\text { Posterior }\end{array}$ & 14 vs 13 & $\begin{array}{l}\text { Kyphosis, VAS, } \\
\text { RM, ODI }\end{array}$ & 118 months & $\begin{array}{l}\text { Radiological and functional results were } \\
\text { similar }\end{array}$ \\
\hline
\end{tabular}

R: Retrospective, RCT: Randomized clinical trial, SF-36: Short-Form 36, VAS: Visual Analogue Scale, ODI: Oswestry Disability Index, RM: Roland and Morris disability questionnaire.

operation time, hospital stay and cost significantly lower in posterior group. In contrast, both loss of correction and final kyphosis, and functional scores were similar in our study. We think that the most important reason underlying these conflicting findings is that Wang and Liu have performed 1 lower and 1 upper posterior instrumentation and fusions which have been shown to fail in several previous studies $(2,16)$. Similarly, blood loss was higher in combined group in the present study.
Some previous studies also compared anterior only versus posterior instrumentation for TL burst fractures $(8,12,14,20,25,31)$. Although, the study design regarding treatment choices are different from our study, the conclusions and clinical implications of these studies are worth discussing here. There are some advantages of anterior surgery such as the ability to perform canal decompression, and low rate of correction loss due to anterior support and fusion (12,32). On the other hand, short operation time, low blood loss and low cost are major advantages of posterior surgery (20). These 
advantages and disadvantages are mentioned in almost all studies compared anterior versus posterior surgery. In a recent metanalysis, a total of 179 anterior and 152 posterior TL burst fractured patients were evaluated in 4 randomized clinical and 3 controlled clinical trials. Both anterior and posterior surgery showed similar clinical and radiological results, but posterior surgery was advocated by the authors because anterior approach was associated with longer operative time, greater blood loss and higher cost than the posterior approach (33). However, despite these generally accepted findings, there are some authors who proposed that anterior surgery may be a more advantageous option. Wood et al. defended anterior surgery due to more frequent complications in posterior surgery in their series (31). Similarly, Hitchon et al. proposed that kyphotic deformity can be corrected more safely in anterior surgery (12).

This study has some strengths and limitations. First, this is a RCT and no patient had been lost during follow-up. Second, follow-up duration is long (10 years) enough to demonstrate long term functional and radiological outcomes. However, small number of patients was included in the study and cost analysis was not performed.

\section{CONCLUSION}

The functional and clinical results of short-segment posterior instrumentation and fusion (2 levels above and 1 level below) are similar with those of short-segment combined anterior and posterior instrumentation and fusion when used in the treatment of TL burst fractures in patients without neurological deficit, but the benefits and advantages (lower blood loss, shorter operation, lower cost) of posterior-only surgery are well known. Thus, we recommend posterior-only surgery for this group of patients. Nevertheless, techniques and implants are continuously developing, particularly minimally invasive techniques, and may change the current practice and gain popularity in the future.

\section{REFERENCES}

1. Abudou M, Chen X, Kong X, Wu T: Surgical versus nonsurgical treatment for thoracolumbar burst fractures without neurological deficit. Cochrane Database Syst Rev 6:CD005079, 2013

2. Alanay A, Acaroglu E, Yazici M, Oznur A, Surat A: Shortsegment pedicle instrumentation of thoracolumbar burst fractures: Does transpedicular intracorporeal grafting prevent early failure? Spine (Phila Pa 1976) 26(2):213-217, 2001

3. Been HD, Bouma GJ: Comparison of two types of surgery for thoraco-lumbar burst fractures: Combined anterior and posterior stabilisation vs. posterior instrumentation only. Acta Neurochir (Wien) 141(4):349-357,1999

4. Briem D, Lehmann W, Ruecker AH, Windolf J, Rueger JM, Linhart W: Factors influencing the quality of life after burst fractures of the thoracolumbar transition. Arch Orthop Trauma Surg 124(7):461-468,2004
5. Danisa OA, Shaffrey CI, Jane JA, Whitehill R, Wang GJ, Szabo TA, Hansen CA, Shaffrey ME, Chan DP: Surgical approaches for the correction of unstable thoracolumbar burst fractures: A retrospective analysis of treatment outcomes. J Neurosurg 83(6): 977-983, 1995

6. Denis F: Spinal instability as defined by the three-column spine concept in acute spinal trauma. Clin Orthop 189:6576,1984

7. Denis F: The three column spine and its significance in the classification of acute thoracolumbar spinal injuries. Spine 8:817-831, 1983

8. Esses SI, Botsford DJ, Kostuik JP: Evaluation of surgical treatment for burst fractures. Spine (Phila Pa 1976) 15(7):667673,1990

9. Gnanenthiran SR, Adie S, Harris IA: Nonoperative versus operative treatment for thoracolumbar burst fractures without neurologic deficit: A meta-analysis. Clin Orthop Relat Res 470(2):567-577, 2012

10. Graillon T, Rakotozanany P, Blondel B, Adetchessi T, Dufour $\mathrm{H}$, Fuentes S: Circumferential management of unstable thoracolumbar fractures using an anterior expandable cage, as an alternative to an iliac crest graft, combined with a posterior screw fixation: Results of a series of 85 patients. Neurosurg Focus 37(1):E10, 2014

11. Guven O, Kocaoglu B, Bezer M, Aydin N, Nalbantoglu U: The use of screw at the fracture level in the treatment of thoracolumbar burst fractures. J Spinal Disord Tech 22(6):417421,2009

12. Hitchon PW, Torner J, Eichholz KM, Beeler SN: Comparison of anterolateral and posterior approaches in the management of thoracolumbar burst fractures. J Neurosurg Spine 5(2):117125,2006

13. Holdsworth FW: Fractures, dislocations and fracture/ dislocation of the spine. J Bone Joint Surg Br 45:6-20,1963

14. Lin B, Chen ZW, Guo ZM, Liu H, Yi ZK: Anteriorapproach versus posterior approach with subtotal corpectomy, decompression, and reconstruction of spine in the treatment of thoracolumbar burst fractures: A prospective randomized controlled study. J Spinal Disord Tech 2011 (Epub ahead of print)

15. Magerl F, Aebi M, Gertzbein SD, Harms J, Nazarian S: A comprehensive classification of thoracic and lumbar injuries. Eur Spine J 3(4): 184-201,1994

16. McAfee PC, Bohlman HH, Yuan HA: The value of computed tomography in thoracolumbar fractures: An analysis of one hundred consecutive cases and a new classification. J Bone Joint Surg Am 67:89-104, 1985

17. McCormack T, Karaikovic E, Gaines RW: The load sharing classification of spine fractures. Spine 19:1741-1744,1994

18. Park WM, Park YS, Kim K, Kim YH: Biomechanical comparison of instrumentation techniques in treatment of thoracolumbar burst fractures: A finite element analysis. J Orthop Sci 14(4):443-449, 2009

19. Reyes-Sanchez A, Rosales LM, Miramontes VP, Garin DE: Treatment of thoracolumbar burst fractures by vertebral shortening. Eur Spine J 11(1):8-12, 2002 
20. Sasso RC, Renkens K, Hanson D, Reilly T, McGuire RJ, Best NM: Unstable thoracolumbar burst fractures: Anterior-only versus short-segment posterior fixation. J Spinal Disord Tech 19(4):242-248,2006

21. Schnake KJ, Stavridis SI, Kandziora F: Five-year clinical and radiological results of combined anteroposterior stabilization of thoracolumbar fractures. J Neurosurg Spine 20(5):497-504, 2014

22. Schnee CL, Ansell LV: Selection criteria and outcome of operative approaches for thoracolumbar burst fractures with and without neurological deficit. J Neurosurg 86(1):48-55, 1997

23. Shin JK, Goh TS, Son SM, Lee JS: Treatment of thoracolumbar and lumbar unstable burst fractures by using combined and posterior surgery. Journal of Trauma and Injury 29(1):14-21, 2016

24. Siebenga J, Leferink VJ, Segers MJ, Elzinga MJ, Bakker FC, Haarman HJ, Rommens PM, ten Duis HJ, Patka P: Treatment of traumatic thoracolumbar spine fractures: A multicenter prospective randomized study of operative versus nonsurgical treatment. Spine (Phila Pa 1976) 31(25):2881-2890, 2006

25. Stancić MF, Gregorović E, Nozica E, Penezić L: Anterior decompression and fixation versus posterior reposition and semirigid fixation in the treatment of unstable burst thoracolumbar fracture: Prospective clinical trial. Croat Med J 42(1):49-53, 2001

26. Tezeren G, Kuru I: Posterior fixation of thoracolumbar burst fracture: Short-segment pedicle fixation versus long-segment instrumentation. J Spinal Disord Tech 18(6):485-488, 2005
27. Vaccaro AR, Lehman RA Jr, Hurlbert RJ, Anderson PA, Harris M, Hedlund R, Harrop J, Dvorak M, Wood K, Fehlings MG, Fisher C, Zeiller SC, Anderson DG, Bono CM, Stock GH, Brown AK, Kuklo T, Oner FC: A new classification of thoracolumbar injuries: The importance of injury morphology, the integrity of the posterior ligamentous complex, and neurologic status. Spine (Phila Pa 1976) 30(20):2325-2333, 2005

28. Vaccaro AR, Zeiller SC, Hulbert RJ, Anderson PA, Harris M, Hedlund R, Harrop J, Dvorak M, Wood K, Fehlings MG, Fisher C, Lehman RA Jr, Anderson DG, Bono CM, Kuklo T, Oner FC: The thoracolumbar injury severity score: A proposed treatment algorithm. J Spinal Disord Tech 18(3):209-215, 2005

29. Wang J, Liu P: Analysis of surgical approaches for unstable thoracolumbar burst fracture: Minimum of five year follow-up. J Pak Med Assoc 65(2):201-205, 2015

30. Wang J, Zhou Y, Zhang ZF, Li CQ, Zheng WJ, Liu J: Radiological study on disc degeneration of thoracolumbar burst fractures treated by percutaneous pedicle screw fixation. Eur Spine J 22(3):489-494, 2013

31. Wood KB, Bohn D, Mehbod A: Anterior versus posterior treatment of stable thoracolumbar burst fractures without neurologic deficit: A prospective, randomized study. J Spinal Disord Tech 18 Suppl:S15-S23, 2005

32. Wood KB, Buttermann GR, Phukan R, Harrod CC, Mehbod A, Shannon B, Bono CM, Harris MB: Operative compared with nonoperative treatment of a thoracolumbar burst fracture without neurological deficit: A prospective randomized study with follow-up at sixteen to twenty-two years. J Bone Joint Surg Am 97(1):3-9, 2015

33. Xu GJ, Li ZJ, Ma JX, Zhang T, Fu X, Ma XL: Anterior versus posterior approach for treatment of thoracolumbar burst fractures: A meta-analysis. Eur Spine J 22(10):2176-2183, 2013 